$\Phi$ акторы риска развития инфекционновоспалительного процесса нижних мочевых путей

\author{
А.А. Камалов, Л.А. Ходырева, А.А. Дударева, А.Н. Низов
}

ФГОУ ВПО «Московский государственный университет имени М.В. Ломоносова» 119991, Российская Федерация, Москва, Ленинские горы, д. 1

Персистенция микроорганизмов, их высокая выживаемость и резистентность - одни из причин, поддерживающие симптомы заболеваний нижних мочевых путей. Они могут длительно сохраняться и значительно снижать качество жизни пациентов с рецидивирующим хроническим инфекционно-воспалительным процессом в стенке мочевого пузыря даже после эрадикации возбудителя.

В последние годы исследования в клинической микробиологии отражают серьезные качественные и количественные изменения в структуре инфекционной заболеваемости, что в большей степени связывают с изменением патогенности бактерий.

Гены «островов патогенности» контролируют синтез различного типа адгезинов, инвазинов, гемолизинов, токсинов (гемолизина, цитотоксического некротизирующего фрактора-1 и др.), системы поглощения ионов железа, важных для размножения и жизнедеятельности возбудителя в тканях.

Обнаружение генетических детерминант дает возможность по-новому взглянуть на процесс эволюции бактерий, понять причину быстрого фрормирования и распространения вирулентных штаммов и развитие инфекционновоспалительного процесса в нижнем отделе мочевого тракта, что может объяснять различную тяжесть патологического процесса и выраженность симптомов поражения нижних мочевых путей.

Ключевые слова: гены патогенности, E. coli, инфекционно-воспалительный процесс, нижние мочевые пути. 


\title{
Risk factors causing the development of infection and inflammation of the lower urinary tract
}

\author{
Lomonosov Moscow State University \\ GSP-1, Leninskie Gory, Moscow, 119991, Russia
}

A.A. Kamalov, L.A. Khodyreva, A.A. Dudareva, A.N. Nizov

\begin{abstract}
Persistence as well as high survival rate and resistance of microorganisms belong to the key reasons promoting symptoms of lower urinary tract diseases. They can stay active for a long time and can substantially deteriorate the life quality of patients suffering from chronic infections and inflammations in the wall of the urinary bladder even after the eradication of the pathogen.

Recent studies in the field of clinical microbiology reflect serious qualitative and quantitative changes in the infection incidence structure, which is mainly related to changes in the bacterial pathogenicity.

Pathogenicity island genes control the synthesis of different adhesins, invasins, hemolysins and toxins (hemolysin, cytotoxic necrotizing factor type 1, etc.) as well as iron ion absorption system, which are essential for the pathogen propagation and activity in tissues.

The determination of genetic determinants will provide a new insight into the bacterial evolution process and will help to understand the reason of prompt formation and propagation of virulent strains as well as fast development of the infection and inflammation in the lower urinary tract, which may explain different severity of the pathology and symptoms of the lower urinary tract.
\end{abstract}

Key words: pathogenicity genes, E. coli, infection and inflammation, lower urinary tract.

Corresponding author: Khodyreva60@mail.ru. Vestnik Dermatologii i Venerologii 2015; 2: 63—67.

Инфрекционно-воспалительный процесс мочеполовой системы в амбулаторной практике занимает второе место по обращаемости после ОРВИ [1]. Воспалительный процесс в мочевом пузыре ассоциируется с симптомами нижних мочевых путей (СНМП), приводя к потере трудоспособности и инвалидизации пациентов, тем самым представляя собой социальноэкономическую проблему.

Распространенность рецидивирующих инфекций мочевых путей зависит от возраста и пола, возникает чаще у женщин, чем у мужчин (1:3) [2]. К фракторам риска развития рецидива хронического цистита относят наличие анатомических и функциональных нарушений нижних мочевых путей, использование спермицидов, смену сексуальных партнеров, наличие мочевой инфекции в детском возрасте, а также рецидивирующее течение иноекционно-воспалительного процесса мочевого пузыря у матери и другие фракторы [3, 4].

Обострение хронического цистита может развиваться на фроне недержания мочи, цистоцеле, остаточной мочи и при изменении защитных свойств уротелия [5, 6].

Уротелий - это не только обычная защита мочевого пузыря от инфекций, это особенная ткань, регулирующая его фрункцию и играющая роль в патогенезе других заболеваний. Существуют доказательства, что в патогенезе хронических воспалительных заболеваний мочевого пузыря первым шагом может быть потеря гликозаминогликанов слизистого слоя с последующим нарушением фрункции органа, проявляющегося повышенной сократительной функцией детрузора $[7,8]$.

При хроническом воспалении слизистой мочевого пузыря в ней обнаруживаются дефекты в виде рас- 
ширения просветов между клетками эпителия. В результате микротравм защитного слоя раздражающие химические вещества, содержащиеся в моче, могут воздействовать на нервные волокна подслизистого слоя, вызывая нейрогенное воспаление, тем самым поддерживая ирритативные симптомы [8, 9].

Персистенция микроорганизмов, их высокая выживаемость и резистентность - одни из причин, поддерживающие симптомы заболеваний нижних мочевых путей. Они могут длительно сохраняться и значительно снижать качество жизни пациентов с рецидивирующим хроническим инфекционно-воспалительным процессом в стенке мочевого пузыря даже после эрадикации возбудителя.

Предполагают, что длительный воспалительный процесс в мочевом пузыре может приводить к развитию хронической субэпителиальной ишемии и гипоксии, которые в одно и то же время повреждают эпителий, снижая его регенераторную способность, и нарушают его фрункцию $[10,11]$.

Биологически активные вещества, воздействуя на определенные рецепторы, способствуют развитию патологической повышенной чувствительности мочевого пузыря, сокращению его гладкой мускулатуры за счет раздражения С-волокон. Особенностью чувствительных волокон, расположенных под уротелием, является образование сплетения в области шейки мочевого пузыря. Повреждения последних, по всей видимости, при рецидивирующих инфекционно-воспалительных процессах приводят к гиперчувствительности мочевого пузыря и развитию гиперактивности, что поддерживает воспаление в стенке мочевого пузыря и СНМП [10, 12, 13].

Большинство случаев мочевой инфекции вызывается микроорганизмами семейства Enterobacteriaceae и их ассоциациями. Их частое выделение из мочи приводят как один из аргументов восходящего пути инфицирования [14]. Этиологическим фрактором негоспитальной и госпитальной инфекции в большем проценте случаев регистрируется представитель семейства Enterobacteriaceae, условно-патогенный фракультативный анаэроб - кишечная палочка, которая является по праву «королевой» мочевой инфекции. Впервые она была выделена из фекалий человека в 1885 г. Т. Эшерихом.

Начиная с 90-х годов проведено не одно исследование по изучению эпидемиологии инфекций нижних и верхних мочевыводящих путей. В последнем международном многоцентровом исследовании «ДАРМИС» (2010-2011), в котором принимали участие медицинские центры России, Беларуси, Казахстана, было изучено 987 внебольничных штаммов микроорганизмов. Доля представителей семейства Enterobacteriaceae составила 83,5\%, из них кишечная палочка являлась возбудителем воспалительного процесса в нижних мочевых путях у 63,5\% пациентов [15].
Ассоциированный инфекционно-воспалительный процесс, вызываемый различными микроорганизмами, нельзя считать просто соединением двух или более инфекций. В организме пациента возникают сложные и неодинаковые по значению связи, определяющиеся разными отношениями между микроорганизмами и реакциями макроорганизма. Это может приводить к длительному малосимптомному хроническому течению заболевания в мочевых путях, трудно поддающемуся лечению [16].

По данным различных авторов, сочетание нескольких возбудителей урогенитальных заболеваний варьировало от 52 до $98 \%$ [16, 17].

В последние годы исследования в клинической микробиологии отражают серьезные качественные и количественные изменения в структуре инфекционной заболеваемости, что в большей степени связывают с изменением патогенности бактерий.

Так как воспаление в нижних мочевых путях проявляется разнообразными патологическими процессами, протекающими в органах и тканях, то первоначально считалось, что патогенные свойства бактерий формируются с помощью редких и уникальных механизмов [18].

В ранних исследованиях П. Брода (1982) была обнаружена локализация многих вирулентных факторов микроорганизмов на плазмидах и фрагах [19]. Позже стало ясно, что гены патогенности, переносимые фагами и плазмидами, не способны вызвать в организме хозяина патологические изменения, и их роль в эволюции патогенных бактерий явно была преувеличена [20].

Последующие исследования обнаружили, что большая часть так называемых фракторов патогенности располагается на хромосомах отдельными кластерами из функционально связанных групп генов. Последовательности этих кластеров отличались от большей части генома, что предполагает их чужеродное происхождение. Позже подобные структуры были найдены на плазмидах, однако они не охватывали всего многообразия таких структур, имеющихся на хромосомах. Эти наблюдения позволили выдвинуть концепцию «островов патогенности», расположенных на дискретных и часто имеющих чужеродное происхождение участках ДНК, кодирующих группы вирулентных признаков [14] (таблица).

Гены «островов патогенности» контролируют синтез различного типа адгезинов, инвазинов, гемолизинов, токсинов (гемолизина, цитотоксического некротизирующего фактора-1 и др.), системы поглощения ионов железа, важных для размножения и жизнедеятельности возбудителя в тканях [21].

Группы этих генов способны к горизонтальному и вертикальному перемещению, встраивание их происходит в строго определенные сайты бактериальной ДНК - «горячие точки». Предполагается, что данный механизм изменения патогенности бак- 
Таблица

Характеристика отдельных «островов патогенности» $E$. coli

\begin{tabular}{|c|c|c|c|c|}
\hline Микроорганизм & Наименование & Стабильность & Функция & Размер, Кб \\
\hline \multirow[t]{2}{*}{$\begin{array}{l}\text { Уропатогенные } \\
\text { E. coli } 536\end{array}$} & $\begin{array}{c}\text { Остров патогенности } \\
\text { I (Pai I) }\end{array}$ & Нет & Альфра-гемолизин & 70 \\
\hline & Pai II & Нет & $\begin{array}{c}\text { Альфа-гемолизин, prf (фимбриии, адгезивные } \\
\text { к клеткам хозяина), транскрипционные активаторы } \\
\text { хромосомных генов }\end{array}$ & 190 \\
\hline \multirow[t]{2}{*}{ Уропатогенные E. coli J96 } & (Pai I) & - & $\begin{array}{c}\text { Альфра-гемолизин, рар (фиммбрии, адгезивные } \\
\text { к клеткам хозяина), последовательности } \\
\text { IS-элементов, последовательности R-плазмид, } \\
\text { последовательности фага P4 }\end{array}$ & $>170$ \\
\hline & Pai II & Нет & $\begin{array}{c}\text { Альфра-гемолизин, pis (фимбрии, } \\
\text { адгезивные для клеток хозяина), } \\
\text { цитотоксический некротизирующий ффактор } \\
\text { I типа, последовательности IS-элементов, } \\
\text { последовательности фага P4, Omp R гомолог }\end{array}$ & 106 \\
\hline
\end{tabular}

терий играет важную роль в фрормировании патогенных вариантов различных видов бактерий, в том числе эшерихий.

В основе изменения патогенности условно-патогенных штаммов кишечной палочки лежит структурная модификация бактериальной ДНК, связанная с миграцией генетических детерминант «островов патогенности» между бактериями различных видов. Особенности структурной организации этих мобильных генетических элементов определяют высокую вероятность их экспрессии, в связи с чем разработка последних методом полимеразной цепной реакции (ПЦР) при тестировании клинических штаммов может использоваться для оценки их потенциальной патогенности [21].

С помощью ПЦР возможны выявление у изолятов, принадлежащих к родам Escherichia, Serratia, Klebsiella, Enterobacter и Citrobacter, генов, ассоциируемых с патогенным потенциалом бактерий, и прогнозирование течения воспалительного процесса у больных с урогенитальной инорекцией [22].

Адгезия бактерий на эпителии мочевого пузыря играет первостепенную роль в развитии иноекционного процесса, и она состоит из нескольких стадий - приближения, неспецифического взаимодействия поверхностей микроба и мембран и затем взаимодействия адгезинов с определенными рецепторами. Известно, что гены рар $C$ контролируют синтез фимбрий Р типа и гены Fim A детерминируют синтез фимбрий 1-го типа в составе «островов патогенности» уропатогенных Escherichia coli [22].

Соотношение генов, отвечающих за фимбриальные структуры, может объяснять или отсутствие симптомов или показывать способность к обсеменению микроорганизмом тканей и распространению воспалительного процесса в мочеполовых путях.
Как правило, микроорганизм вызывает минимальный ответ «хозяина», если рар-ген подавлен или инактивирован в штаммах [23].

Ген токсинообразования (CNF1) способствует выработке биологических компонентов с высокой активностью, вызывая функциональные и структурные повреждения в организме «хозяина», редко встречается у штаммов E. coli при инфекциях нижних мочевых путей [22].

По данным нашего исследования, отсутствие изменений со стороны других систем и органов при остром воспалительном процессе в мочевом пузыре, в отличие от пациентов с выраженной воспалительной реакцией в организме, связано с очень небольшой встречаемостью у E. coli таких генов патогенности, как hly A, hly B, ігр-2, CNF1 [22].

Таким образом, обнаружение генетических детерминант, входящих в состав «островов патогенности» условно-патогенных микроорганизмов, определяющих их адгезивную, колонизирующую, цитотоксическую и энтеротоксическую активности, дает возможность по-новому взглянуть на процесс эволюции бактерий, понять причину быстрого фрормирования и распространения вирулентных штаммов и развитие инфекционно-воспалительного процесса в нижнем отделе мочевого тракта, что может объяснять различную тяжесть патологического процесса и выраженность симптомов поражения нижних мочевых путей. Изучение фракторов риска развития инфекционно-воспалительного процесса нижних мочевых путей может позволить разработать критерии этиологической значимости, основанные на изучении указанных биологических характеристик возбудителей, и улучшить диагностику инфекций мочеполовых путей. I 


\section{Литература}

1. Rossiyskie natsional'nye rekomendatsii «Antimikrobnaya terapiya i profilaktika infektsiy pochek, mochevyvodyashchikh putey i muzhskikh polovykh organov». М, 2013; 5. [Российские национальные рекомендации «Антимикробная терапия и профилактика инфекций почек, мочевыводящих путей и мужских половых органов». М., 2013; (5)].

2. Hooton T.M. Reccurent urinary tract infection in women. Int J Antimicrob Agents 2001; 17 (4); 259-268.

3. Lundstredt A.C., Leijonhufvud I., Ragnarsdottir B. et al. Inherited susceptibility to acute pyelonephritis: a family study of urinary tract infection. J Infect Dis 2007; 195 (8); 1227-1234.

4. Hooton T.M. Reccurent urinary tract infection in women. Int J Antimicrob Agents 2001; 17 (4); 259-268.

5. Nicolle L.A. Asimptomatic bacteriuria in the elderly. Infect Dis Clin North Am 1997; 11 (3): 647-662.

6. Sufiyarov A.D. Aktual'nye problemy konservativnoy urologii. Menopauzal'nyy tsistit. Tsistalgiya. Pod red. R.Kh. Galeeva. Kazan'; MEDDOK 2007, 128. [Суфияров А.Д. Актуальные проблемы консервативной урологии. Менопаузальный цистит. Цисталгия. Под ред. Р.Х. Галеева. Казань; МЕДДОК 2007, 128].

7. Damiano R., Cicione A. The role of sodium hyaluronate and sodium chondroitin sulphate in the management of bladder disease. Ther Adv Urol 2011; 3 (5); 223-232.

8. Geppetti P., Nassini R., Materazzi S., Benemei $S$. The concept of neurogenic inflammation. BJU Int 2008; 101 (Suppl.3); 2-6.

9. Parsons C.L, Lilly J.D, Stein P. Epithelial dysfunction in nonbacterial cystitis (interstitial cystitis). J Urol 1991; 145 (4); 732—735.
10. Siracusano S., Cucchi S., Ciciliato S. et al. Urinary levels of giycosaminoglycans in patients with idiopathic detrusor overactivity. Int Urogynecol J Pelvic Floor Dysfunct 2009; 20 (12); $1477-1480$.

11. Nomiya M., Sagawa K., Yazaki J. et al. Increased bladder activity is associated with elevated oxidative stress markers and proinflammatory cytokines in a rat model of atherosclerosis-induced chronic bladder ischemia. Neurourol Urodyn 2012; 31 (1); 185-189.

12. Avelino A., Cruz C., Nagy I., Cruz E. Vanilloid receptor expression in the rat urinary tract. Neuroscience 2002; 109 (4); 787-798.

13. Arya L.A., Northington G.M., Asfaw T. et al. Evidence of bladder oversensitivity in the absence of an infection in premenopausal women with a history of recurrent urinary tract infections. BJU Int 2012; 110 (2); 247-251.

14. Supotnitskiy M.V. Mikroorganizmy,toksiny i epidemii. Uchebnik 2010, glava 1.3-12. [Cyпотницкий М.В. Микроорганизмы,токсины и эпидемии. Учебник 2010, глава 1.3-12].

15. Rossiyskie natsional'nye rekomendatsii «Antimikrobnaya terapiya i profilaktika infektsiy pochek, mochevyvodyashchikh putey i muzhskikh polovykh organov», 2013; 20-25. [Российские национальные рекомендации «Антимикробная терапия и просилактика инсрекций почек, мочевыводящих путей и мужских половых органов», 2013; 20—25].

16. Dorofeev S.P., Kamalov A.A. Sovremennye vzglyady na problemu khronicheskogo prostatita. RMZh 2003; 11 (4): 736-742. [Дopodpeев С.П., Камалов А.А. Современные взгляды на проблему хронического простатита. РМЖ 2003; 11 (4): 736-742].

17. Adaskevich V.P. Infektsii peredavaemye polovym putem. M,1999; 327. [Адаскевич В.П. Инфекции, передаваемые половым путем. M,1999; 327].
18. Micenková L., Štaudová B., Bosák J. et al. Bacteriocin-encoding genes and EXPEC virulence determinants are associated in human fecal Escherichia coli strains. BMC Microbiol 2014; 14: 109.

19. Brod P. Plazmidy, M,1982; 157. [Брод П. Плазмиды, М,1982; 157].

20. Mecsas J.J., Strauss E.J. Molecular mechanisms of bacterial virulence: type III secretion and pathogenicity islands. Emerg Infect Dis 1996; 2 (4); 270-288.

21. Bondarenko V.M., Fialkina S.V., Lysenko T.I. Geneticheskie determinanty patogennosti shtammov Escherichia coli, izolirovannykh iz mochi i fekaliy detey s razlichnymi klinicheskimi variantami infektsiy mochevoy sistemy. Children Infections 2004; 3: 21-23. [Бондаренко В.М., Фиалкина С.В., Лысенко Т.И. Генетические детерминанты патогенности штаммов Escherichia coli, изолированных из мочи и фекалий детей с различными клиническими вариантами инсрекций мочевой системы. Детские инсекции 2004; (3): 21-23].

22. Vershinin A. Ye., Bondarenko V.M., Khodyreva L.A., Perepanova T.S. Implication of detection of genomic markers of pathogenicity islands in Escherichia coli in urological practice. Klinicheskaya Laboratornaya Diagnostika 2006; 10; 50-51. [Вершинин А.Е., Бондаренко В.М, Ходырева Л.А., Перепанова Т.С. Значение обнаружения геномных маркеров островов патогенности у Escherichia coli в урологической практике. Клиническая лабораторная диагностика 2006; (10); 50—51].

23. Kashkin K.P., Bekhalo V.A. A strategy of immune laboratory tests in the infectious disease clinic (lecture). Klinicheskaya Laboratornaya Diagnostika 2004; (3): 23—25. [Кашкин К.П., Бехало В.А. Стратегия иммунолабораторных исследований в клинике инсекционных болезней (лекция). Клиническая лабораторная диагностика 2004; (3): 23—25].

об авторах:

А.А. Камалов - д.м.н., профессор, ФГОУ ВПО «МГУ им М.В. Ломоносова», ФФМ, кафедра урологии и андрологии, зав. кафредрой, член-корреспондент РАН

Л.А. Ходырева - Д.м.н., доцент, ФГОУ ВПО «МГУ им М.В. Ломоносова», ФФМ, кафредра урологии и андрологии

А.А. Дударева - К.М.Н., ассистент, ФГОУ ВПО «МГУ им М.В. Ломоносова», ФФМ, касредра урологии и андрологии

А.Н. Низов — аспирант, ФГОУ ВПО «МГУ им М.В. Ломоносова», ФФМ, кафедра урологии и андрологии

\section{Конфликт интересов}

Авторы заявляют об отсутствии потенциального конфликта интересов, требующего раскрытия в данной статье 